\title{
Un révolutionnaire allemand, Georg Forster (1754-1794)
}

Philippe Goujard

\section{(2) OpenEdition \\ 1 Journals}

Édition électronique

URL : https://journals.openedition.org/ahrf/1964

DOI : 10.4000/ahrf.1964

ISSN : 1952-403X

Éditeur :

Armand Colin, Société des études robespierristes

\section{Édition imprimée}

Date de publication : 1 décembre 2005

Pagination : 260-263

ISSN : 0003-4436

\section{Référence électronique}

Philippe Goujard, « Un révolutionnaire allemand, Georg Forster (1754-1794) », Annales historiques de la Révolution française [En ligne], 342 I octobre-décembre 2005, mis en ligne le 05 avril 2006, consulté le 23 avril 2022. URL : http://journals.openedition.org/ahrf/1964 ; DOI : https://doi.org/10.4000/ahrf. 1964

Ce document a été généré automatiquement le 23 avril 2022

Tous droits réservés 


\title{
Un révolutionnaire allemand, Georg Forster (1754-1794)
}

\author{
Philippe Goujard
}

\section{RÉFÉRENCE}

Marita GILLI (éd.), Un révolutionnaire allemand, Georg Forster (1754-1794), Paris, Éditions du C.T.H.S., 2005, 734 p., ISBN 2-7355-0586-3, $18 €$

1 On doit à Marita Gilli d'avoir mis enfin à la disposition des lecteurs ignorants de la langue allemande une traduction et édition critique des principaux textes écrits par $\mathrm{G}$. Forster, âme des Jacobins de Mayence, pendant la première période d'occupation française, parmi lesquels ses discours à la Société des Jacobins de Mayence, à la Convention nationale rhéno-germanique qui décida le rattachement de la rive gauche du Rhin à la France, ses Tableaux parisiens rédigés pendant son exil après la perte de Mayence par la République, et surtout peut-être sa Correspondance, avant tout adressée à sa femme, à son beau-père, à ses frères et amis du club rhénan et au général custine, commandant en chef des troupes d'occupation, au total la quasi-totalité des ses lettres envoyées du 20 octobre 1792 au 4 janvier 1794 où il dit pressentir sa fin prochaine, jugement lucide puisqu'il mourut le 20 janvier suivant.

2 Tout auteur de recension de livres doit faire le délicat. On ne dispose ici que des textes écrits par Forster pendant la Révolution de Mayence. Or, Forster n'avait pas attendu la grande tourmente qui balaya l'Europe pour se faire un nom dans la République européenne des Lettres. Mais il va sans dire que M. Gilli nous dit tout ce qu'on doit savoir sur ce que fut Forster avant Forster. Né en 1754 d'une famille lointainement originaire du Yorkshire et installée en Prusse polonaise au début du XVII siècle, Georg dut presque tout son savoir à son père, modeste pasteur, qui lui apprit à comprendre 17 langues, mais lui transmit surtout de solides connaissances scientifiques et un goût du concret qu'il conservera sa vie durant. Bien que n'ayant fréquenté ni le lycée ni 
l'université, Forster fut tout sauf un autodidacte au savoir parcellisé, superficiel, et, comme il est habituel en pareil cas, immodeste.

3 Sa dilection pour le concret allait s'enrichir de ses voyages, en Russie d'abord où il visita les colonies d'Allemands installées par Catherine II, et surtout dans le Pacifique puisqu'il participa en 1772 au deuxième voyage autour du monde de Cook, grâce à son père qui avait accepté de s'embarquer à la condition que son fils fut de l'expédition. Il en fit un récit exhaustif, livrant toutes les observations qu'il avait pu faire sur la géographie, la faune, la flore et les mœurs des habitants, occasion pour lui d'étayer, mais sur des faits réels, les théories du «bon sauvage » et de l'égalité naturelle entre les hommes, quel que soit le niveau de leur civilisation matérielle. À 23 ans, il était célèbre.

4 Succès sans lendemain. Il fut la coqueluche des salons anglais, mais de façon éphémère. Mais sa renommée en Allemagne lui permit de se faire une place comme professeur à l'Université de Kassel, poste obtenu grâce à l'appui de son père qui avait, lui, obtenu une chaire à l'Université de Göttingen, plus prestigieuse. Kassel fut en fait pour lui un lieu d'enfermement dans lequel il étouffa, comme tous les « intellectuels » allemands de condition modeste des années 1780 , asphyxiés dans un pays morcelé, corseté par une société d'ordres rigide. Il allait passer quatre ans dans la principauté de Kassel, archétype de ces États "de poche" allemands du XviII siècle, avec son prince tyrannique, ses cercles de jeu, ses filous, ses chevaliers d'industrie, ses aigrefins, ses aventuriers de tout acabit et ses nobles auxquels la morgue servait de talent: bref un milieu propice à l'austère réflexion intellectuelle. Autre déception pour Forster, son appartenance aux Rose-Croix, occasion pour lui de s'adonner à l'alchimie, juste le temps de s'apercevoir qu'elle n'était qu'une forme de charlatanisme comme une autre. Relevons qu'il ne se laissa pas prendre, comme d'autres dont R. Darnton nous a, naguère, donnés les noms, au piège à sots de la fumisterie mesmérienne. Il quitta vite la loge des Rose-Croix, mais continua ses relations avec des maçons plus sérieux. Au passage, il avait épousé Thérèse Heyne, fille d'un célèbre archéologue de Göttingen - où il allait de temps à autre s'aérer l'esprit -. Elle était laide, intelligente et cultivée, et le mariage ne fut pas une réussite. Il fut un moment professeur à l'Université de Vilna avant d'obtenir un poste de bibliothécaire à Mayence. L'atmosphère intellectuelle $\mathrm{y}$ était un peu plus supportable qu'à Kassel. La reprise d'anciennes amitiés comme celle nouée avec Sommering, la découverte de nouveaux amis, comme les frères Humboldt, ses études, ses voyages dont un fait au long du Rhin avec Alexandre Humboldt en 1790 dont il publia un récit où, pour la première fois, apparaît chez lui le souci de la politique largement né de son observation de la Révolution contre-révolutionnaire brabançonne éclairèrent sans doute l'obscénité pathétique de son quotidien.

5 Forster ne fut pas un aigri, comme certains petits esprits le disent lorsqu'ils prétendent expliquer les choix révolutionnaires des gens de sa condition. Ses "années d'apprentissage " ont fait de Forster un homme de convictions philosophiques et politiques fortes. Fils des Lumières, il est un optimiste, un croyant du progrès. Croyant, mais point dévot : cet optimiste est doué d'un réalisme robuste, fruit de sa formation scientifique, de son sens scrupuleux de l'observation précise et de ses expériences de voyageur. Pour lui le progrès ne va pas sans lutte. En matière philosophique, il est un matérialiste en ceci que le monde réel est indépendant des représentations que l'entendement humain peut s'en faire. Il fut aussi un scientifique reconnu, mais mon ignorance en la matière m'interdit de donner plus de précisions. 
6 En matière politique, ses séjours en Angleterre, où la politique américaine du gouvernement lui a ôté ses illusions sur la nature du régime politique, à Cassel où il a vécu la médiocrité mesquine de la Kleinstaaterei, et à Vilna où il a pris conscience des méfaits d'une oppression absolutiste autrement plus lourde que celle régnant en Allemagne, ont construit sa vision politique. Il dénonce l'oppression absolutiste et féodale, liée à la religion d'État, quelle qu'elle soit, qui assure l'obéissance des peuples en les endormant. S'il affirme avec les penseurs allemands de son temps l'importance de la Bildung, à leur différence, il la conçoit comme un procès de construction de la liberté politique, et point seulement intérieure. Cette liberté doit être aussi économique et il milite pour l'abolition du système corporatif.

7 La Révolution française, pour laquelle sa sympathie devient telle qu'il refuse une proposition de traduire Burke pour mieux faire connaître au public allemand Th. Paine, enrichit sa pensée politique, avant que l'entrée dans Mayence des troupes de Custine l'engage dans le combat politique. Après avoir peu de temps hésité, comme il l'explique dans une lettre à son beau-père du 24 octobre 1792 (p. 324), il adhère à la Société des Jacobins de Mayence. Il en devient le leader d'opinion, présent sur tous les fronts, y compris quand il s'agit d'intervenir auprès de Custine pour défendre des amis, comme le citoyen Mieg, injustement dépouillé de ses biens (pp. 438-439), et surtout pour lui rappeler que les pillages, les réquisitions et les contributions excessives ne peuvent avoir qu'un effet désastreux sur l'attitude des populations de moins en moins disposées à se rallier aux Français, malgré le bon accueil qu'elles auraient d'abord fait aux troupes françaises : du moins est-ce ce qu'il affirme dans sa Description de la Révolution à Mayence (p. 154). Le peu d'illusion qu'il peut nourrir sur la force du mouvement révolutionnaire allemand fait de lui le plus ardent des partisans du rattachement de Mayence à la République française. On sait la suite. La défaite française l'oblige à rester en France où il termine sa vie dans la pauvreté et dans l'oubli, malgré une rencontre en juillet 1793 avec Théroigne de Méricourt (p. 535). Mais, le 19 mai, il avait été l'hôte du banquier Lecoulteux (p. 526).

8 Bien évidemment, l'expérience pratique de Forster a donné force, renouvelé et enrichi les convictions qu'il pouvait avoir en 1790. Je me contenterai de reprendre le résumé qu'en donne M. Gilli. D'abord, son idée que le mouvement historique est le produit de l'affrontement de forces antagonistes, et, par conséquent, la nécessité de la violence, thème récurrent de ses écrits politiques (par exemple, p. 100) et de sa correspondance. Affirmations qui seront reprises un petit demi-siècle plus tard par un autre Rhénan, mais avec une pertinence, une robustesse et une ampleur tout autres.

9 Ensuite, la notion de «moment favorable», autre manière de dire "théorie des circonstances ». Précisément, l'entrée des troupes françaises était ce moment qui offrait l'occasion d'entraîner dans le mouvement révolutionnaire des Allemands incapables de mener par leurs propres forces la moindre action de subversion sociale. Et Forster jugeait même les habitants de la rive gauche du Rhin moins apathiques, s'il était possible, que les autres Allemands. Ce fut la seconde raison qui le convainquit de rattacher le pays de Mayence à la « République des Francs ", l'occupation française ayant donné le coup de grâce à un Saint Empire romain germanique à l'agonie : « Le Rhin est là pour le bonheur de l'Allemagne; il doit être la frontière qui sépare de l'Allemagne le pays des Républicains » (p. 335). Précurseur de la notion de frontières naturelles, il sacrifia toute ambition d'étendre le règne de la Liberté à l'Allemagne toute entière, n'envisageant jamais son unité : vision d'ensemble assurément plus étrécie que celle 
des Jacobins italiens. S'agissant de l'immaturité politique des Allemands, il distingue (pp. 127-128) entre la langueur des urbains, bourgeois comme artisans, moralement corrompus par le système de domination sociale et politique de la Kleinstaaterei et son atmosphère délétère peu propice à bronzer la vertu, de la combativité du monde paysan, comme si les paysans eux aussi avaient pris conscience que la présence française ouvrait un moment favorable pour piller les métairies seigneuriales et faire la grève des dîmes. Face à ce mouvement paysan, l'attitude de Forster est ambiguë. Il l'approuve et le trouve excessif tout à la fois. On n'ose imaginer qu'il ait craint que cette agitation n'ampute ses modestes émoluments universitaires, pour l'essentiel constitués par le produit des dîmes (p. 334). Mais, après tout, un révolutionnaire, fût-il d'une irréfutable sincérité, cela mange tous les jours (p. 340).

10 Enfin, son expérience mayençaise et, plus encore, son séjour dans le Paris de l'an II, où il put juger des effets de la politique de liberté des prix, l'amena à rejeter le libéralisme économique et à affirmer qu'il ne pouvait y avoir d'égalité politique sans égalité sociale.

11 Concluons. Un des apports essentiels du travail de M. Gilli est aussi de montrer, à travers une trajectoire individuelle - mais quel individu et quelle trajectoire! - les limites du mouvement révolutionnaire allemand. Ainsi se demande-t-on si c'est par naïveté politique ou par préjugé culturel de classe que Forster regrette que la Société des Jacobins de Mayence ne compte parmi ses adhérents ni «juristes habiles», ni " commerçants bien considérés », ni " prêtres intelligents et vertueux », mais qu'» on a accepté sans examen un foule d'étudiants rustres et d'autres jeune gens encore imberbes et d'autres personnes qui n'étaient pas connues pour leur moralité, en partie pour augmenter le nombre des membres, en partie pour donner de la vigueur au principe d'égalité » (pp. 180-181). Jugement qui peut paraître contradictoire avec sa dénonciation de l'apathie de la plèbe urbaine.

Il manquait décidément aux Jacobins allemands la hardiesse des Jacobins italiens et pas seulement à propos de la question de l'unité nationale. 